\title{
Resilience and Coping with the Traumatic Experience during Adolescence
}

\author{
Madrudin Shamsudinovich Magomed-Eminov \\ Olga Grigoryevna Kvasova \\ Olga Olegovna Savina
}

Lomonosov Moscow State University

\author{
Doi:10.5901/mjss.2015.v6n6s1p470
}

\begin{abstract}
Development of information technologies led to increasing in traumatic situations at teenagers, including to distribution of systematic aggression from contemporaries on the Internet and social networks. Younger teenagers who only start using actively the Internet are especially vulnerable, without realizing all possible dangers, and for the first time face prosecution and mockeries (cyberbullying). Research is devoted to the detection of features of a coping of children with traumatic experience and need of creation of effective ways of rendering psychological assistance to teenagers - to the victims of a cyberbullying. It is proved that the situation of a cyberbullying is a traumatic experience for children. The coping phenomenon with traumatic experience in a situation of a cyberbullying was analyzed from the point of view of gender and age distinctions, the subjective importance of a situation, and existence in the past of the child of a similar situation. Communication between a semantic orientation of the personality and ways of a coping with traumatic experience in children's age was in addition studied (children with L-semantic orientation are more often characterized by resilience manifestations, use constructive strategy of a coping while for group with D-semantic orientation higher values on scales of a discharge, a not coping and leaving are characteristic). In this work, the traumatic situation is considered to be a life situation that shows to the child semantic tasks. Results of this research will help to create the most complete idea of features of coping with traumatic experience in children's age and can be used when rendering psychological assistance to the children who appeared in a difficult life situation.
\end{abstract}

Keywords: psychological injury, coping, cyberbullying, teenagers, resilience.

\section{Introduction}

Traditionally authors of the researches devoted to traumatic experience at children are focused on its negative side, leaving indifferently such aspects as adaptation, self-preservation, overcoming and growth of the personality (MagomedEminov, 2007). In modern psychology, the increasing weight is purchased by researches of semantic (meaning) components of the psychological injury (Bonnano, 2005; Herman, 1992; Janoff-Bulman R., 2002; Lifton, 1988; PanterBrick C., 2012). In the semantic concept of the injury (Magomed-Eminov, 2007; Magomed-Eminov, 2009 \& MagomedEminov, 2014) in addition to the attach case of the traumatic situation through not daily mode of existence (invasion of the non-existence of life), threat of existence of the person, the emphasis is placed and on the subjective importance of the occurred event for the individual. In it there are transformations of sense, valuable and semantic contradictions, semantic new growths where the traumatic situation acts as the life situation showing to the person semantic tasks are created, and the injury is understood as work of the wound, binding process, are entered concept $L$ and D-meanings, meaning of life and meanings of death which ratio form the general fundamental semantic orientation the personality (Kvasova, 2013). In this approach, the coping is understood more widely than traditional treatment of the coping (Kryukova, 2010 \& Belinskaya, 2014) - behavioral, emotional and cognitive components of the response to the traumatic situation. The person who was affected by traumatic experience processes it, carrying out semantic work of the personality on the formation of the life of the personality. Coping is not only worked on recovery but also protection and development. Efficiency of the coping with traumatic experience can be estimated through effects of the extreme traumatic situation the triad "frustration - resilience - growth", or otherwise: maladaptive effects (to which refer post-traumatic stressful frustration (Kroeberg, 1963)); the adaptive - growth and resilience (Magomed-Eminov, 2008 \& Magomed-Eminov, 2015) "Resilience") (Bonanno, 2013; Card, 2015; Masten A., 2014 \& Panter-Brick, 2012).

Children endure traumatic situations differently than adults (Finkelhor, 2010; Gupta, 2011 \& Le Broque, 2010). Children are dependent on adults and often interpret the situation as traumatic, relying on the reaction of adults. In researches of specifics of traumatic experience in children's age complexity causes that children I cannot often realize 
that the situation is traumatic (Nikolskaya, 2000 \& Pyatnitskaya, 2008). It is possible to refer poverty of symptomatology (manifestation of separate symptoms, but not all complex) to specifics of the children's injury; smaller intensity and short duration of manifestation of symptoms, lack of the stage of mobilization; often - disorganization of behavior (MagomedEminova, 2015). For adults the most traumatic usually are discrete events, for children's age collision with chronically operating environment factors, such as poverty or ill-treatment (Bonanno G. is characteristic., 2005; Bonanno G. \& Diminich E., 2013), lack of care and pathological nature of relationship with mother (Boulby J., 2003; Winnikot D.V., 2004), divorce of parents (Figdor G., 2006), problems in relationship with contemporaries (Bochaver \& Kholmov, 2013, \& Enikolopov, 2014) and others. The number of researchers claim that children, often, most sharply and take the similar situations subject to influence of the psych injuring situations hard, often have the heavy intrapersonal conflicts, are inclined to manifestation of socially not approved behavior forms (Pyatnitskaya, 2008). There are data that children show in traumatic situations, resilience, courage (Bonanno, 2004; Masten, 2014; Ungar, 2011; Magomed-Eminov, 2007, \& Magomed-Eminova, 2015).

The Bulling, or persecution, is defined as the purposeful, systematic aggressive behavior directed at another person (Olweus, 1993). In the teenage and children's environment, it is usually expressed that the children having the high status and authority among the contemporaries "attack" on weak and unprotected without the reasons seen on that (Camodeca \& Goossens, 2005). Now in the nursery and the teenage environment the bullying problem, or systematic aggression and persecution in relation to the child from contemporaries as became the traumatic situation even more actual in view of emergence of new means of manifestation of aggression: possibility of free video filming by children of each other, active use of the Internet and social networks (Peter, 2013, \& Swearer, 2013). Use of the Internet is connected with exposure of the child to different risks: content (information concerning to damnification to health, sexual content), electronic (viruses, spam), consumer (theft of online money, copyright violation), and also to communication risks (the grooming, the cyber bullying) (Soldatova, 2011). Allocate the following types of the cyberbullying: flaming (short emotional skirmishes); attacks (systematic insults); slander; cajolery and distribution of confidential information; online alienation; cyber prosecution; the happis leaping (placement in video Internet with violence scenes). The special group of risk is made by younger teenagers who only start using actively the Internet, but do not realize all possible dangers (Belinskaya, 2014). Having fallen the victim of the cyberbullying, the teenager often gets to the stalemate: he cannot cope independently with the situation independently, but is afraid to report about it to adults, being afraid to lose access to Internet space.

Let's allocate the main approaches to the coping problem: dispositional approach in which at the choice of strategy of the coping identity of the subject is decisive factor (Freud, 1993), situational approach which considers influence of different aspects of the environment on cope behavior (Lazarus \& Folkman, 1984). including cognitive (the assessment of threat, cash resources, the assessment of success of the coping), behavioral and emotional components; the integrative approach considering interaction of factors of the personality and the situation (Kryukova, 2004; Bonanno, 2004, \& Masten, 2001) the concept " Resilience" (Card, 2015, \& Masten, 2014), described: as psychological invulnerability (Rutter, 1987), capability to successful adaptation as a result of stability maintenance (Bonanno \& Diminich, 2013), capability to support the optimum level of functioning of the organism (Yehuda \& LeDoux, 2007), capability of dynamic systems to adapt to external influences (Masten A., 2001), process of mobilization of resources for wellbeing maintenance (Panter-Brick \& Eggerman, 2012). To the factors protecting from the mental injury, inherent children, carry the Ego force, availability of reliable attachment (Sandler, et al, 2008, \& Rutter, 1987). It is considered that resistance to vital difficulties forms in the childhood and efforts of parents are necessary for its development: encouragement of the initiative of the child, approval, creation of the various favorable environment

The main emphasis in researches of the coping with traumatic experience in children's age is traditionally placed on studying of cognitive, emotional and behavioral manifestations while the traumatic situation is the life situation, which shows to the child semantic tasks for which decision transformation of the semantic sphere of the personality is necessary.

\section{Methods and Materials}

For the purpose of detection of features of the coping with traumatic experience in children's age empirical research in which children and teenagers aged from 10 till 14 years participated (pupils of 5-7 classes of schools of Moscow and Mr. Chernogolovki) was conducted. Number of Examinees - 219 people (107 boys, 112 girls).

Hypotheses: 1) the situation of the cyberbullying is potentially traumatic experience for children's age; 2) there are gender and age distinctions in coping methods with traumatic experience in the cyberbullying situation; 3 ) there is the communication between the subjective importance of the situation of the cyberbullying and methods of the coping with it; 
4) there is the communication between availability in the past of the situation of the cyberbullying and coping methods with traumatic experience in the cyberbullying situation; 5) there is the communication between the semantic orientation of the personality and methods of the coping with traumatic experience in children's age.

Techniques: 1) the questionnaire which is independently developed by us "Assessment of the situation of the cyber bullying" which represents to the floor - the projective technique including the description story about the cyberbullying situation concerning the teenager; unfinished offers and rating scales of the importance of the situation, its effects, methods of permission of this situation, awareness of examinees with the similar situation on own experience; 2) questionnaire of coping strategy for children school age (Nikolskaya \& Granovskaya, 2000); 3) The youthful coping-scale (in T.L. Kryukova's adaptation, 2010)]. The quantitative assessment of the received results was performed using the SPSS Statistics 21.0 program, criteria the chi-square, Mann-Whitney's U-criterion, Student's T-criterion, the coefficient of correlation of Spearmen is used. The content analysis of unfinished offers using criterion the chi-square.

\section{Results and Discussions}

Research is directed at studying of factors of overcoming of the situation of the cyberbullying at teenage age. The age group investigated by us the strengthened operation of the mechanism of identification with the contemporary therefore; we assumed is characteristic that estimating probability of emergence of certain symptoms in the hero of the described history, examinees estimate probability of emergence of similar situations at themselves. 16\% of examinees (35 people) at least once acted, as the victim of the cyber bullying, and, boys was insignificant more, than girls.

Table 1 - Distribution of the pupils who were exposed to the cyber bullying

\begin{tabular}{|c|c|c|c|c|}
\hline \multirow{2}{*}{ Classroom } & \multicolumn{2}{|c|}{ Number of the pupils who were exposed to the cyber bullying } & $\%$ \\
5 & $M$ & $F$ & Total & $15 \%$ \\
6 & 6 & 7 & 13 & $14 \%$ \\
7 & 9 & 2 & 11 & $19 \%$ \\
Total: & 4 & 7 & 11 & $16 \%$ \\
\hline
\end{tabular}

For pupils of 5 and 6 classes the situation of the cyberbullying is more traumatic, than for pupils of 7 classes. Fifthgraders estimate probability of emergence of dreadful dreams in comparison with 6 and 7 classes $(p=0,001)$ significantly above, is significant below - aggressive actions (in comparison with 6 classes - $p=0,05$, in comparison with 7 classes $r=0,008$ ). In comparison with 7 classes pupils of 5 classes highly appreciate probability of repetition of this situation in the future $(r=0,047)$, probability of emergence of fears and concerns $(r=0,05)$, below - probability of social isolation $(r=0,05)$. Pupils of 6 classes are higher, than seventh-graders, estimate probability of painful somatic reactions $(r=0,012)$, fears $(r=0,02)$, the notions of compulsion $(r=0,04)$, difficulties in concentration $(r=0,05)$. Summing up the result told above, we could tell that there are age distinctions in estimates of effects of the situation of the cyberbullying. In 5 and 6 classes estimates of probabilities of symptoms of invasion and hyper excitement are higher, and in 7 classes avoiding tendency symptoms are estimated above.

Significant distinctions on the floor were also revealed. Girls above boys estimate probability of that the child in such situation will feel like the derelict $(r=0,018)$, to feel helpless $(r=0,033)$, and it will be difficult to it to concentrate $(r=0,05)$. The pupils having experience of collision with the cyberbullying situation above others estimate the probability of emergence of dreadful dreams $(r=0,05)$ and desires to break rage on people around $(r=0,04)$. On other scales, significant distinctions were not detection.

For more detailed understanding of ideas of examinees of the cyberbullying situation we included the additional points concerning in the questionnaire whether someone from the environment of examinees came up against the similar situation and probabilities of emergence of such situation in life examinees (Figure 1). 


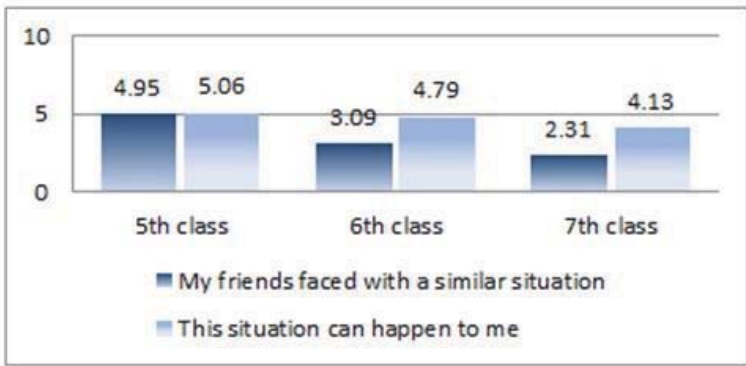

Figure 1 - Average values of estimates of probability of emergence of the situation of the cyberbullying in life of examinees and their people around

On the category "my acquaintances came up against the similar situation", significant distinctions between age are received: between 5 and 6 classes $-r=0,000$, between 6 and 7 classes $-r=0,049$. The children in the past having experience of the situation of the cyberbullying are inclined to estimate probability of that from friends will become the victims of the cyber bullying $(r=0,008)$. Significant distinctions on the floor it is not revealed. On the category "the similar situation can happen to me," significant distinctions between 5 and seven classes were received $(r=0,09)$. Also, the examinees who already acted the victim in cyberbullying situations, estimate the possibility of above that they can appear in the similar situation $(\mathrm{r}=0,001)$.

Derivation (72\%), persistent study (67\%), concern (65\%), accessory (65\%), the problem resolution (64\%), search of support from friends $(62 \%)$, hope for the miracle $(62 \%)$, focusing on positive sides of the situation (62\%), active recreation (62\%) and social support (61\%) appeared the most widespread strategy of the coping with the cyberbullying situation among pupils of the 7th class. The strategy of the request for the help of professionals (36\%) and public actions $(37 \%)$ are less often used.

The statistical analysis revealed gender specifics: girls use strategy of social support $(r=0,000)$, problem resolutions $(r=0,006)$, works and achievements $(0,002)$, concern $(r=0,006)$ and the appeal to spirituality $(r=0,000)$ significantly more often. Boys more often than girls use derivation strategy $(r=0,009)$, active recreation $(r=0,001)$ and public actions $(r=0,01)$. Distinctions on availability in the past of the situation of the cyberbullying were revealed: examinees who already came up against the similar situation, use the strategy of the not coping $(r=0,05)$ less often. Examinees who highly appreciate the importance of the situation of the cyberbullying, use ignoring strategy $(r=0,05)$, from the low - the discharge $(r=0,05)$ and concerns $(r=0,05)$ more often.

The qualitative analysis of features of the coping with traumatic experience is carried out (unfinished offers, "The assessment of the situation of the cyber bullying, and also the probable outcome of this situation concerning feelings, thoughts and actions of the hero of the history offered by us in the questionnaire questionnaire). Answers of examinees were analyzed from the point of view of semantic orientation (Magomed-Eminov, 2009). To L-semantic (life centered meanings) orientations were referred the subcategories of answers that are characterized by the dominance of aspiration of the adoption of the life of the personality, the positive orientation. The subcategories connected with destruction, the negative orientation were carried to D-semantic orientation (death-centered meanings).

As a result, we divided examinees into two groups: 1) CL semantic orientation (56 people); 2) CD semantic orientation (163 persons). We received the following significant distinctions on coping methods with a traumatic experience in the cyberbullying situation between groups with L- and D- semantic orientation. In 5 and 6 classes: examinees with L-semantic orientation use strategy "I apologize more often or I tell the truth" $(\mathrm{r}=0,03)$, "I try to relax and remain quiet" $(r=0,024)$, "I walk, I run, I ride the bicycle" $(r=0,045)$. The strategy "are more widespread in a group with $D$ semantic orientation I try to forget" $(r=0,006)$, "I go crazy" $(r=0,041)$. In 7 classes: examinees with L-semantic orientation use strategy the problem resolution $(r=0,001)$, positive focus $(r=0,000)$, and examinees with $D$-semantic orientation - the not coping $(r=0,039)$ and the discharge $(r=0,008)$ more often.

\section{Discussion of Results}

The received results allow claiming that the situation of the cyberbullying is a potentially traumatic experience for pupils of 5-7 classes. Examinees highly appreciate probability of emergence in the hero of the shown situation of the majority of 
symptoms, which can arise in children and teenagers after a collision with the traumatic situation. Besides, the average importance of the situation of the cyber bullying (7,25 on the 10-mark scale) speaks about the high subjective importance of the similar situation. Interpretation of results of the statistical analysis allows assuming that pupils of 5 and 6 classes estimate the probability of emergence of symptoms of invasion and hyper excitement above, and in 7 classes avoiding symptoms are estimated above. Possibly, it can be connected with the fact that at teenage age the leading activity is interpersonal communication with contemporaries, and in total with active development of consciousness and the selfassessment the situation of the cyberbullying is for them "restraining the personality".

Our data testify for the benefit of the hypothesis of the existence of gender and age distinctions in coping methods with a traumatic experience in the cyberbullying situation. For 5 and 6 classes the most widespread strategy of the coping with the cyberbullying situation along with aspiration to consider the situation are derivation and corporal contact. Thus for pupils of 5 classes leaving in the distracting activity (viewing of the TV and listening to music) is more characteristic, deeper considering of the situation that assumes more frequent use of cognitive strategy of the coping is peculiar to 6 graders. In the 7th classes also the most widespread strategy is derivation and the problem resolution. However search of social support and approval is also of great importance from people around. However, thus high values on scales of concern, hope for the miracle and focusing on positive sides of the situation that speaks about the frequent use of both constructive and not constructive methods of the coping were received. It is also possible to note that, in general, pupils of 7 classes use more extensive the circle of methods of the coping, than pupils of 5 and 6 classes.

It was revealed that girls, on the one hand, use the emotional strategy of the coping and strategy of search social, and with another - problem-oriented methods of behavior (in 7 classes) more often. To boys more inherent the strategy directed on derivation and leaving (games, active recreation). Communication between the subjective importance of the situation of the cyberbullying and methods of the coping with it is found. It was revealed that in examinees who highly appreciate the importance of the situation of the cyberbullying, use strategy of ignoring and leaving more often; for group with the low importance strategy of the discharge and considering of the situation are more characteristic.

Data confirm communication between availability in the past of the situation of the cyberbullying and coping methods with a traumatic experience in the cyberbullying situation. Examinees who already came up against the cyberbullying situation more often look for supports at relatives and actively act independently, in comparison with those who did not come up earlier against the similar situation while the second use strategy of the not coping more often.

Communication between the semantic orientation of the personality and methods of the coping with a traumatic experience in children's age is revealed. Examinees with L-semantic orientation use the constructive strategy of the coping while for the group with D-semantic orientation higher values on scales of the discharge, the not coping and leaving were revealed more often. The obtained data allow speaking about the importance of forming at school students of the L-semantic orientation.

\section{Conclusions}

In this work the traumatic situation was considered as the life situation that shows to the child semantic tasks, and the coping situation - is a potentially traumatic experience for pupils of 5-7 classes. There are gender and age distinctions in coping methods with a traumatic experience in the coping situation. The subjective importance of the situation of the coping is connected with coping methods with it. There is the communication between availability in the past of the situation of the cyberbullying and coping methods with a traumatic experience in the cyberbullying situation. Communication between the semantic orientation of the personality and methods of the coping with a traumatic experience in children's age is revealed. Results of research promote forming of the better understanding of features of the coping with traumatic experience at teenagers that can be used when rendering psychological assistance to the children and teenagers who appeared in the difficult life situation. These data, in our opinion, could be helpful to work on psychological education of school students, teachers and parents of teenagers on whom the subjective importance of the situation for the child usually depends on. Significant adults - parents and teachers - often go into extremes, underestimating or excessively exaggerating the value of the status of the cyberbullying that complicates receipt of the help in the extreme situation for the teenager.

Practical experience of the Department of Psychology of extreme psychological help at Lomonosov Moscow State University in establishing a program of psycho-pedagogical technology assistance, taking into account the role of the positive factors of extremality (Magomed-Eminov, 2007) including the impact of the Internet environment. The tasks include prevention, cessation of kiberbulling and psycho-pedagogical support of teenagers caught or could be victims of kiberbulling. Prevention of improper behavior in the Internet involves the development tools, filtering inappropriate content in social networks, and training the adolescents basic safety rules, creating the possibility of an adequate and self- 
expression of feelings in the social space without aggression, victimization. Such work should be carried out with young people in various forms - conducting interviews, the creation of individual and collective projects (such as "Security risks in social networking," "Features of communication of adolescents in social networks"). The specific situation of kiberbuling that occurred in the classroom, psychologists and educators direct the effect on relations within the group of adolescents, helping to improve mutual understanding, cooperation and respect. An important aspect of school psychologists is Propaedeutic work with adults - teachers and parents of adolescents, including risk communication in social networks, the need for limited personal information, and establish trust in contact with the teenager, avoiding direct authoritarian restrictions on Internet communication. Contact of psychological service with parents, teachers and teen community allows you to respond quickly to incidents of kiberbulling, preventing the development of the negative effects of trauma.

\section{References}

Blaya, K. \& Cyber bullying (2012) / K.Blaya//Children in information society. No. 10. pp. 40-45.

Enikolopov S.N. (2014) In the situation of the cyberbullying of age restrictions there is no S.N. Enikolopov///Children in the information society. №. 16. pp. 37-41.

Krasova, O.G. (2013) Transformation of the temporary perspective of the personality in the extreme situation / O.G. Krasova//the Abstract of the thesis of the candidate of psychological sciences. M.

Kryukova, T.L. (2010) Methods of studying of coping behavior: rub coping-scale/T.L. Kryukova - Kostroma: KGU of N.A. Nekrasov. Avantitul. pp. 64.

Magomed-Eminov, M.Sh. (2007) Positive psychology of the person. From the psychology of the subject to life psychology / M. Sh. Magomed-Eminov:v of 2 t. M.: PARF. pp. 560.

Magomed-Eminov, M.Sh. (2009) Activity and semantic approach to the psychological transformation of the personality / M. Sh. Magomed-Eminov. The abstract of the thesis on competition of the academic degree of the doctor of psychological sciences. M.

Magomed-Eminov, O. I. (2015) Psychological analysis of the phenomenon of resilience / O. I. Magomed-Eminov//Actual problems of humanitarian and natural sciences. No. 1. pp. 206-210.

Macfarlane, A. (2003) Injury and its challenge to society (societies). Macfarlane, B. Van der Kolk//Advisory psychology and psychotherapy. No. 1. pp. 7-30.

Nikolskaya, I.M. (2000) Psychological protection at children / I.M. Nikolskaya, R. M. Granovskaya. Spb: Speech. pp. 342.

Pyatnitskaya, E.V. (2008) Psychological assistance to the children and teenagers enduring the psycho injuring events / E. V. Pyatnitskaya. Balashov: Nikolaev.

Soldatova, G.U. (2011) Cyberbullying in the school environment: situation difficult online and coping methods/G. U. Soldatova, E.Yu. Zotova//Educational policy. No. 5 (55). pp. 11-22.

Bonanno, G.A. (2005) Resilience in the Face of Potential Trauma/ G.A. Bonanno// Current Directions in Psychological Science. vol. 14. pp. 135-138.

Bonanno, G.A. (2013) Annual research review: Positive adjustment to adversity-Trajectories of minimal-impact resilience and emergent resilience/ G. A.Bonanno, E. D.Diminich// Journal of Child Psychology and Psychiatry. 54. pp. 378-401.

Camodeca, M. (2005) Aggression, social cognitions, anger and sadness in bullies and victims/ M. Camodeca,F. A. Goossens// Journal of Child Psychology and Psychiatry. Vol. 46. pp. 186-197.

Card, N.A. (2015) Methodological Considerations in Studying Individual and Family Resilience/ N.A. Card \& M.A. Barnett// Interdisciplinary Journal of Applied Psychology. Family relations. pp. 120 - 133.

Finkelhor, D. (2010) Lifetime assessment of poly-victimization in a national sample of children and youth/ D. Finkelhor, R. Ormrod, H. Turner/l American Journal of Preventive Medicine. 38 (3). pp. 323-330.

Gupta, S. (2011) Anger expression and adaptation to childhood sexual abuse: The role of disclosure/ S. Gupta [et. al.]// Psychological Trauma: Theory, Research, Practice, and Policy. Vol 3(2). pp. 171-180.

Herman, J. (1992) Trauma, and Recovery: The Aftermath of Violence - From Domestic Abuse to Political Torture/ J. Herman - New York: Basic Books.

Janoff-Bulman, R. (2002) Shattered Assumptions: Towards a New Psychology of Trauma/ R. Janoff-Bulman - N-Y.: Free Press. pp. 272.

Kroeberg, T.C. (1963) The coping functions of the ego mechanisms. The study of lives/ T.C. Kroeberg - New York: Atherton.

Lazarus, R.S. (1984) Stress, appraisal, and coping/ R.S. Lazarus, S. Folkman - New York: Springer.

Le Brocque, R. (2010) The Course of Posttraumatic Stress in Children: Examination of Recovery Trajectories Following Traumatic Injury/ R.LeBrocque, J.Hendrikz, J.Kenardy/l Journal of Pediatric Psychology. Vol. 35(6). pp. 637-645.

Lifton, R.J. (1988) Understanding the traumatized self. Human adaptation to extreme stress/ R.J. Lifton - N.Y.: Plenium Press.

Masten, A. (2014) Global Perspectives on Resilience in Children and Youth/ A. Masten// Child Development. Vol.85. pp. 6-20.

Olweus, D. (1993) Bullying at School: What We Know and What We Can Do (Understanding Children's Worlds) - Oxford UK: Blackwell Publishers. pp. 140.

Panter-Brick, C. (2012) Understanding Culture, Resilience, and Mental Health: The Production of Hope/C.Panter-Brick, M.Eggerman/ Ungar, M., editor. - New York: Springer. pp. 369-386.

Peter, J. (2013) The Effects of Internet Communication on Adolescents' Psychosocial Development/ J. Peter, P.M. Valkenburg// The 
International Encyclopedia of Media Studies, First Edition. Volume V: Media Effects/Media Psychology. - Blackwell Publishing Ltd. pp. 31-51.

Rutter, M. (1987) Psychosocial resilience and protective mechanisms/ M. Rutter// American Journal of Orthopsychiatry. 57. pp. 316-331.

Sandler, I. (2008) Handbook of Bereavement Research and Practice/ I. Sandler [et.al] - Washington, D.C: American Psychological Association.

Schwarzwald, J. (1994) Stress reactions of school-age children to the bombardment by Scud missiles: a 1-year follow-up/ J.Schwarzwald [et. al.]// Journal of Traumatic Stress. 7(4). pp. 657-667.

Swearer, S. (2009) Prevention and intervention. Realistic strategies for schools/S.Swearer, D.L.Espelage, S.A. Napolitano- N-Y, London: The Guilford Press.

Ungar, M. (2011) The social ecology of resilience: Addressing contextual and cultural ambiguity of a nascent construct/ M. Ungar// American Journal of Orthopsychiatry. №81. pp. 1.

Belinskaya, E.P. (2014) Sovladaniye with difficulties during the era of new information technologies: opportunities and restriction / E.P. Belinskaya//Psychological researches. T. 7, No. 38. pp. 2.

Magomed-Eminov, M.Sh. (2014) the Analysis of modern models of the psychological injury from the point of view of the cultural and activity paradigm / M. Sh. Magomed-Eminov//the Theory and practice of social development (the electronic magazine). 2014. №. 17. 